\title{
Pseudorabies Virus Infection Induces Endoplasmic Reticulum Stress Through the PERK and IRE1 Pathways of Unfolded Protein Response in Suspension-cultured BHK-21 Cells
}

\section{Li Chen}

East China University of Science and Technology

\section{Minshu Ni}

Jiangsu University

\section{Waqas Ahmed}

East China University of Science and Technology

Yue Xu

Jiangsu Academy of Agricultural Sciences

\section{Xi Bao}

Jiangsu Academy of Agricultural Sciences

\section{Tenghan Zhuang}

Jiangsu Academy of Agricultural Sciences

Lei Feng ( $\nabla$ fenglei@jaas.ac.cn )

Jiangsu Academy of Agricultural Sciences https://orcid.org/0000-0002-1195-2424

Meijin Guo

ECUST: East China University of Science and Technology

\section{Research Article}

Keywords: Pseudorabies virus, unfolded protein response, endoplasmic reticulum stress, BHK-21 cells

Posted Date: January 25th, 2022

DOI: https://doi.org/10.21203/rs.3.rs-1268050/v1

License: (c) (1) This work is licensed under a Creative Commons Attribution 4.0 International License. Read Full License 


\section{Abstract}

Pseudorabies virus (PRV) is a pathogen of swine resulting in devastating disease. Some viral infections can cause endoplasmic reticulum (ER) stress and unfolded protein response (UPR) to restore ER homeostasis. However, the mechanism of how PRV induces ER stress and UPR activation remains unclear. Here, levels of proteins or transcriptional factors of three UPR pathways were examined in suspension-cultured BHK-21 cells to investigate PRV-induced ER stress. Results showed that PRV triggered ER stress and UPR of the host cells with the upregulated expression of glucose-related protein $78 \mathrm{kD}$ and 94 kD (GRP78 and GRP94). The protein kinase RNA-like ER kinase (PERK) pathway was activated to upregulate ATF4, CHOP, and GADD34 expression. Additionally, the inositol requiring kinase 1 (IRE1) pathway was triggered by splicing of X box-binding protein 1 (XBP1) mRNA and the enhanced expression of $\mathrm{p} 58^{\mathrm{IPK}}$ and EDEM1. Furthermore, our data demonstrated that PRV took advantage of ER stress to accelerate its replication with the activation of the PERK and IRE1 pathways in suspensioncultured BHK-21 cells, and the glycoprotein B played a crucial role in ER stress.

\section{Introduction}

Pseudorabies virus (PRV), a member of the Alphaherpesviridae subfamily in the family Herpesvirideae, consists of a linear dsDNA molecule of 143 kilobases (Klupp et al. 2004; Deng et al. 2019), which causes Aujeszky's disease in swine and other animals (Sun et al. 2016). Swine is the natural host and reservoir of PRV (Zhang et al. 2019a). Before 2011, immunization with Bartha-K61 vaccine had been proved a safe and effective method to prevent the disease until an unprecedented epidemic of pseudorabies affected Chinese pig herds, causing severe impact on domestic swine production (Zhou et al. 2017).

The endoplasmic reticulum (ER) is a vital organelle involved in cell metabolism, calcium homeostasis, protein synthesis, protein folding, and protein trafficking (Hetz and Papa 2018). Additionally, most secreted transmembrane proteins enter the lumen of the ER for maturation before being transported (Karagoz et al. 2019). Various external stimuli, such as pathogen invasion, glucose deprivation, and chemical treatment, may disrupt the ER homeostasis and lead to the accumulation of unfolded or misfolded proteins, which causes ER stress and a cytoprotective signaling cascade termed as unfolded protein response (UPR) (Walter and Ron 2011; Liu et al. 2017; Ellgaard et al. 2018). The UPR is an immediate cellular response to mediate physiological fluctuations in the folding load of the ER with three main branches triggered by three transmembrane ER stress sensors: the protein kinase RNA-like ER kinase (PERK), activating transcriptional factor-6 (ATF6), and inositol requiring protein-1 (IRE1) (Isler et al. 2005; Karagoz et al. 2017; Zou et al. 2019). Under unstressed conditions, the ER chaperone 78-kDa glucose-regulated protein (GRP78/BIP) binds to the luminal domains of the sensors to keep them inactive (Jiang et al. 2017). Although the three branches of UPR are independent, they are tightly bound and intercrossed in a signaling network (Ron and Walter 2007; Fung et al. 2015). Dissociation of GRP78 from these sensors caused by the ER stress results in the activation of these sensors, which triggers the stimulation of a complex signal transduction cascade and downstream activation of UPR related genes (Ibrahim et al. 2019; Kopp et al. 2019). 
The process of PERK activation by ER stress involves oligomerization, autophosphorylation, and direct phosphorylation on serine residue 51 of the a subunit of eukaryotic initiation factor 2 (elF2a).

Phosphorylated elF2a (P-elF2a) prevents the formation of ribosomal initiation complexes, leading to global mRNA translational attenuation. However, P-elF2a paradoxically upregulates the translation of several other mRNAs, such as encoding activating transcription factor 4 (ATF4) mRNA. This factor can induce the expression of the transcription factor C/EBP homologous protein (CHOP), which further activates transcription of growth arrest and DNA-damage-inducible protein 34 (GADD34) to direct P-elF2a dephosphorylation and to restart global mRNA translation (Jaud et al. 2019; Zhao et al. 2020). Both IRE1 and ATF6 play essential roles in activating transcriptional pathways that increase the capacity of protein folding, transportation, and degradation in cells (Li et al. 2018; Tan et al. 2018). Activated IRE1 cleaves a 26-nucleotide intron from X-box binding protein 1 (XBP1) mRNA under stress conditions. Spliced XBP1 (sXBP1) mediates regulated IRE1-dependent decay (RIDD) and encodes a basic leucine zipper (b-ZIP) transcription factor that upregulates UPR target genes in the ER-associated protein degradation (ERAD) pathway, such as ER-degradation-enhancing-a-mannosidase-like protein 1 (EDEM1) and p58 IPK (Sharma et al. 2017). When unfolded or misfolded proteins accumulate in the ER, ATF6 will be translocated to the Golgi, where it is cleaved by Golgi-resident site 1 and site 2 proteases (S1P and S2P) to generate an activated ATF6(N) b-ZIP (basic leucine zipper) transcription factor (Jin et al. 2017). Activated ATF6 translocates to the nucleus to induce genes that encode protein chaperones to restore ER homeostasis, such as GRP78, GRP94, protein disulfide isomerase (PDI), and ER protein 57 (ERp57) (Zhao et al. 2019).

Several studies have reported that virus infection induces ER stress, and some viruses utilize host cell membrane to establish their own membrane components for progeny virions in the process of ER stress (Mukhopadhyay et al. 2005; Reid et al. 2018). To restore ER homeostasis, some viruses activate pathways of the UPR for their replication in infected cells. On the one hand, UPR upregulates the expression of the ER chaperones to promote virus infection. On the other hand, translational attenuation is also mediated by UPR, such as ERAD, RIDD, and apoptosis, which limits viral replication (Zhang and Wang 2012). The ER stress induced by classical swine fever virus (CSFV) promotes CSFV production, in which the IRE1 pathway plays an important role (He et al. 2017). Transmissible gastroenteritis virus (TGEV) triggers the PERK-eiF2a pathway of UPR and negatively regulates TGEV replication, representing a vital aspect of host innate responses to invading pathogens (Xue et al. 2018). PRV infection induces ER stress and activates the IRE1-XBP1 pathway in PK-15 cells (Yang et al. 2019). However, it remains unclear how the ER stress and UPR are induced by PRV infection in suspension-cultured BHK-21, which served as a vaccine manufacturing cell line.

In this study, we systematically examined the induction of the three branches of the UPR and measured the expression levels of UPR sensor genes to explore UPR activation during PRV infection. This work will provide new insights into understanding the mechanisms of replication and pathogenesis of PRV.

\section{Materials And Methods}




\section{Cells, viruses and viral propagation}

Adherent BHK-21 cells were cultivated in Dulbecco's minimal essential medium (DMEM; Invitrogen, Carlsbad, CA, USA) containing $10 \%$ FBS (Gibco-BRL, Carlsbad, CA, USA) at $37^{\circ} \mathrm{C}$ and $5 \% \mathrm{CO}_{2}$. Primary suspension-cultured BHK-21 cells were adapted and cultured in a $250 \mathrm{~mL}$ shaking flask with $75 \mathrm{~mL}$ of MD910 (Merck KGaA, Darmstadt, Germany) containing 1\% FBS on Kühner shaker at $180 \mathrm{rpm}, 37^{\circ} \mathrm{C}$ and $5 \% \mathrm{CO}_{2}$. The PRV-NJ strain was isolated and preserved by our laboratory. The Reed-Muench method was used to determine viral titers, using $50 \%$ tissue culture infections dose $\left(\mathrm{TCID}_{50}\right)$ in adherent BHK-21 cells.

Suspension-cultured BHK-21 cells and viruses were cultured in a set of 4 parallel 1-L bioreactors (Applikon, Netherland). The cultivation conditions were $160 \mathrm{rpm}, 37^{\circ} \mathrm{C}, \mathrm{pH}$-controlled at 7.2, and dissolved oxygen (DO) controlled at $50 \%$. When viable cell density reached $4 \times 10^{6} \mathrm{cells} / \mathrm{mL}$, the same volume of media was added, followed by the inoculation of the PRV-NJ strain at a 0.01 multiplicity of infection (MOI). The mock-infection and PRV-infection cells were collected at different hours post infection (hpi) until 48 hpi.

\section{Antibodies and reagents}

Antibodies against elF2a (9722S), P-elF2a (3597S), anti-CHOP (5554T), calreticulin (12238T), ATF6 (65880T), ATF4 (11815s), PDI (3501T), a-Tubulin (2144S), $\beta$-Actin (4970T), GAPDH (5014S), anti-FLAG (14793S) were purchased from Cell Signaling Technology. Antibodies against GRP78 (ab21685) and GRP94 (ab3674) were obtained from Abcam. Antibody against GAPDH (10494-1-AP) was purchased from Proteintech. HRP-labelled goat anti-rabbit IgG antibody (62-9520) was purchased from Invitrogen. The ER stress inducer thapsigargin (Tg), and the ER stress inhibitor tauroursodeoxycholic acid (TUDCA) were obtained from Sigma.

\section{RNA extraction, cDNA synthesis, quantitative real-time PCR (qRT-PCR), and XBP1 splicing assays}

PRV-infection samples with the same cell counts at different hours post infection were harvested by centrifugation for $10 \mathrm{~min}$ at the speed of $1000 \mathrm{rpm}$. The supernatant was removed, and total RNA was extracted using RNeasy Mini Kit (Qiagen, Cat.74104) and treated with DNase I before reverse transcription to remove genome DNA. QuantiNova Reverse Transcription Kit (Qiagen, Cat.205413) was used for cDNA synthesis, and QuantiFast SYBR Green PCR Kit (Qiagen, Cat.204054) was used for qRT-PCR in LightCycler 480 II (Roche, Germany). As a loading control $\beta$-actin gene of BHK-21 cells was used for the relative quantification. The fold changing values of target genes were calculated by a $2^{-\Delta \Delta C t}$ method using $\beta$ actin as the reference gene. The primers used for this study are listed in Table 1.

For XBP1 splicing level analysis, PCR was performed for 35 cycles $\left(94^{\circ} \mathrm{C}\right.$ for $30 \mathrm{~s}, 58^{\circ} \mathrm{C}$ for $30 \mathrm{~s}$, and $72^{\circ} \mathrm{C}$ for $30 \mathrm{~s}$ ) with primers, as listed in Table 1. PCR products were separated and visualized on a $2.0 \%$ agarose gels by digesting with Pst I enzyme under UV ImageQuant. The sizes of the PCR products corresponding to the unspliced XBP1 mRNA (UXBP1) were 317bp and $213 \mathrm{bp}$. 


\section{Western blot}

Equal amounts of PRV-infection cells were lysed using RIPA lysis buffer, supplemented with phosphatase and protease inhibitor cocktails (PMSF, Beyotime). The proteins were separated on 12\% SDS-PAGE and transferred onto polyvinylidene difluoride (PVDF) membranes (Millipore). The membranes were blocked with 5\% nonfat milk in Tris-buffered saline containing $0.1 \%$ Tween-20 (TBST) and incubated overnight with primary antibodies at $4^{\circ} \mathrm{C}$. Followed by washing three times with TBST, the membranes were incubated with IgG HRP-linked secondary antibodies for $1 \mathrm{~h}$ at $37^{\circ} \mathrm{C}$, exposed to ECL-2 western blot substrate (Thermo Scientific, Pierce), and imaged using a Tanon 5200 system (Biotanon, Shanghai, China). The protein bands were detected and processed by ImageJ2 software.

\section{Chemical treatment}

Two chemicals with different concentrations $(0,0.001,0.005,0.01$ and $0.02 \mu \mathrm{M} \mathrm{Tg} ; 0,20,40,80$ and 160 $\mu \mathrm{M}$ TUDCA) were respectively supplemented into culture media in combination with PRV inoculation at an $\mathrm{MOI} 0.01$ for 48 hours. All the chemicals were maintained during the whole course of virus infection and replication until the virus was harvested. The Counting Kit-8 (CCK-8, Dojindo) was used to measure cell viability and wester blot was used to detect GRP78 expression in mock-infection cells at $48 \mathrm{~h}$. The viral titer was detected as mentioned above.

\section{Transient expression of the PRV structural proteins}

The coding sequences of PRV glycoproteins $\mathrm{B}, \mathrm{C}, \mathrm{D}, \mathrm{H}, \mathrm{I}, \mathrm{L}$, and $\mathrm{M}(\mathrm{gB}, \mathrm{gC}, \mathrm{gD}, \mathrm{gH}, \mathrm{gl}, \mathrm{gL}$, and $\mathrm{gM})$ were synthesized with Flag tag at C-terminal (Tsingke Biotechnology, Jiangsu, China) and cloned into the pcDNA3.1 (-) vector respectively. When BHK-21 cells were incubated to $70 \%$ confluence in 6 -well culture plates, transient expression of different PRV glycoproteins was performed by transient transfection using Attractene transfection Reagent (Qiagen, Cat.301005) according to the manufacturer's instructions. After 48 hours post transfection, the transfected cells with pcDNA3.1-glycoproteins and pcDNA3.1 empty vector (negative control) and PRV-infection cells (positive control) were lysed using RIPA lysis buffer and analyzed by western blot.

\section{Data analysis}

The data were presented as the mean \pm standard deviation (SD). Two-way ANOVA test was applied for statistical significance assessment, and the difference was presented as $P<0.05\left(^{\star}\right), P<0.01$ (**), and $P$ $\left.<0.001{ }^{(\star \star \star}\right)$.

\section{Results}

\section{PRV infection induces ER stress in suspension-cultured BHK-21 cells}


The suspension-cultured BHK-21 cells were infected at an $\mathrm{MOI}$ of 0.01 , and the relative cell viability and viral titers were detected at 12, 24, 36, 48 and $56 \mathrm{~h}$. Compared to mock-infection cells, the relative cell viability significantly decreased and was only less than $60 \%$ at $56 \mathrm{hpi}$ after PRV infection (Fig. 1A). The growth curve of PRV illustrated that the viral titer exponentially increased and reached a maximal value $\left(8.1 \mathrm{lgTCID}{ }_{50} / \mathrm{mL}\right)$ at $48 \mathrm{hpi}$, then declined at $56 \mathrm{hpi}(\mathrm{Fig} .1 \mathrm{~B})$. The results showed that many cells had been lysed at 56 hpi by PRV infection. Therefore, samples within 48 hours (12, 24, 36 and 48 h) post PRV infection were selected to perform the analysis of ER stress.

We measured the expression and transcription levels of the ER stress markers GRP78 and GRP94 by western blot and qRT-PCR. As shown in Fig. 1C, 1D, and 1E, proteins and mRNA expression levels of GRP78 and GRP94 were significantly upregulated from 36 hpi in PRV-infection BHK-21 cells compared with mock-infection cells, which suggested that ER stress was potentially triggered by PRV infection and replication afterward.

\section{PRV infection triggers the PERK pathway}

The results showed that the level of phosphorylated elF2a was upregulated at $36 \mathrm{hpi}$ (Fig. 2A, 2B). We also measured CCAAT/enhancer-binding protein homologous protein (CHOP), cyclic AMP-dependent transcription factor 4 (ATF4), growth arrest, and DNA damage-inducible protein 34 (GADD34). Expectedly, PERK-elF2 $a$ activation following PRV infection resulted in elevated expression of $\mathrm{CHOP}, \mathrm{ATF} 4$, and GADD34 downstream of elF2a (Fig. 2A, 2B and 2C). Overall, results suggested that PRV infection activated the PERK pathway.

\section{PRV infection activates the IRE1 pathway}

Later, splicing in the XBP1 gene, a characteristic marker for activation of IRE1 signaling, was detected for the IRE1 branch investigation. Activated IRE1 spliced a 26-nucleotide (nt) segment from the unspliced XBP1 (UXBP1) mRNA with its endoribonuclease activity. The translation of this mRNA produced the active 371-amino acid isoform and spliced XBP1 (sXBP1). Splicing of UXBP1 results in loss of the Pst I restriction site located in the intron. The results showed that the spliced form of XBP1 increased from 36 $\mathrm{h}$ by PRV infection, and the RT-PCR products of PRV-infection and mock-infection before 24h were digested by Pst I to produce both the 317 bp and 213 bp fragments (Fig. 3A). The activation of the IRE1XBP1 axis by PRV infection was further confirmed by measuring the transcriptional level of the XBP1 downstream target p58 IPK and EDME1 genes (Fig. 3B), suggesting that PRV infection activated the IRE1 pathway under ER stress.

\section{PRV infection does not trigger the ATF6 pathway}

An active $50 \mathrm{kDa}$ variant of ATF6 comprising the $\mathrm{N}$-terminus was released by splitting full-length ATF6 protein $(90 \mathrm{kDa})$ in response to the ER stress. To determine whether PRV infection induces the ATF6 pathway of the UPR or not, we compared protein and the mRNA levels of endogenous ATF6 and the chaperones calreticulin, calnexin, ERp57, and PDI using qRT-PCR (Fig. 4A, 4B and 4C). No significant 
differences were observed in the mRNA level of these genes with infection time elapsed, suggesting that the ATF6 pathway was not activated by PRV infection.

\section{ER stress facilitates viral replication}

As mentioned above, our results showed that PRV infection induced ER stress in host cells. The effects of ER stress inducer Tg and inhibitor TUDCA treatments on PRV replication were further investigated. Different concentrations of Tg or TUDCA were supplemented into culture media in combination with PRV inoculation at an $\mathrm{MOI} 0.01$. Different concentrations of chemicals were respectively maintained during the whole course of virus infection and replication until the virus was harvested at $48 \mathrm{hpi}$. The results showed that the $\mathrm{Tg}$ treatments promoted ER stress, and TUDCA treatment inhibited ER stress by detecting the GRP78 protein levels in mock-infection cells at $48 \mathrm{~h}$. (Fig. 5A). The relative cell viability was not affected at lower $\mathrm{Tg}$ concentrations $(0.001$ and $0.005 \mu \mathrm{M})$ in mock-infection cells, compared with untreated cells $(0 \mu \mathrm{M} \mathrm{Tg})$ at $48 \mathrm{~h}$. However, under intense ER stress circumstances, when the concentration of $\mathrm{Tg}$ was increased to $0.01 \mu \mathrm{M}$, cell viability dramatically reduced (15\% reduction) (Fig. 5B). The viral titers significantly increased by almost $0.8 \operatorname{lgTCID}_{50} / \mathrm{mL}$ at Tg concentrations of 0.005 and $0.01 \mu \mathrm{M}$ compared to untreated cells by PRV infection (Fig. 5C). Additionally, TUDCA treatment showed no obvious effect on cell viability (Fig. 5B) in mock-infection cells, but viral titers decreased with increasing TUDCA concentration (Fig. 5C). Overall, these results demonstrated that the ER stress induced by a certain concentration Tg promoted PRV replication.

\section{PRV structural proteins trigger UPR pathways}

The structural proteins of PRV were major effectors for virus entry, virion packaging, virion egress, and cell-to-cell viral spread. To further determine whether the glycoproteins, such as gB, gC, gD, gH, gl, gL, and $\mathrm{gM}$, could trigger UPR pathways, the transient expression of these glycoproteins was conducted in BHK21 cells, respectively. The results indicated that these glycoproteins were successfully expressed in BHK21 cells (Fig. 6A). Importantly, our results in Fig. 6B and 6D showed that the expression of gB, gD, and gl significantly enhanced GRP78 and GRP94 expression in BHK-21 cells according to immunoblotting analysis. Furthermore, gB expression upregulated the level of phosphorylated elF2a, and no significantly changes were found in the transfected cells with pcDNA3.1-glycoproteins compared with control (pcDNA3.1 transfected cells) in the ATF6 pathway (Fig. 6B and D). The RT-PCR products were mostly detected by the spliced form of XBP1 in the transfected cells with pcDNA3.1-gB, whereas the RT-PCR products were digested by Pst I to generate $317 \mathrm{bp}$ and $213 \mathrm{bp}$ fragments in other the transfected cells with pcDNA3.1-glycoproteins (Fig. 6C). These results showed that gB triggered PERK and IRE1 pathways and played a key role in ER stress.

\section{Discussion}

Viruses develop different kinds of complex strategies to facilitate their propagation through regulating host cell responses and escaping from certain defense mechanisms. ER stress and the UPR pathways induced by virus invasion have been found in many host cells (Blazquez et al. 2014; Fung et al. 2014; 
Neerukonda et al. 2018). Kaposi's sarcoma-associated herpesvirus (KSHV) infection was involved in the activation of three UPR signaling pathways, but some of UPR downstream transcriptional responses were restricted to support lytic replication (Johnston et al. 2019). Alphaherpesvirus entry into cells required the coordinated action of several structures on the viral surface. The attachment is mediated by multiple viral glycoproteins and a variety of binding receptors. The glycoprotein $B$ is the viral fusion protein, which is responsible for insertion into the host cell membrane and refolding to drive fusion of the viral envelope and cell membrane(Connolly et al. 2021). However, whether PRV induces ER stress of the host and activates the UPR pathways, and their correlation with viral production and structural proteins are not clear. This study will provide new insights into the mechanisms of replication and pathogenesis of PRV.

Molecular chaperones, such as GRP78 and GRP94, are stress-response marker proteins whose overexpression triggers host cells under stress. Our study showed that the expression level of GRP78 and GRP94 were upregulated in PRV-infection cells at $36 \mathrm{hpi}$, suggesting that the ER stress and UPR were activated. Compared with the occasion in other studies (Yang et al. 2019), the upregulation of GRP78 occurred later by PRV infection in this work. It could be attributed to the low $\mathrm{MOI}$ and cell host. Here we used $\mathrm{MOI} 0.01$, which had been optimized as an optimum inoculating parameter in our suspensioncultured BHK-21 cells for PRV vaccine production in bioreactors, while others cultured PRV with adherent cells at a higher MOI of 1.0 in T25 flasks. (Yang et al. 2017; Wang et al. 2018).

Meanwhile, we examined the three branches of UPR pathways, termed PERK, IRE1, and ATF6, using western blot and qRT-PCR. Among the three branches, the PERK pathway was considered to be activated at the early stage of ER stress during virus infection (Liao et al. 2013), and elF2a was phosphorylated at Ser51. However, if the ER stress continues, a downstream signaling molecule of the PERK will be activated, such as ATF4, which further accelerates CHOP expression (Zhou et al. 2016). In this study, enhanced expression of both ATF4 and GADD34 was observed at $36 \mathrm{hpi}$. CHOP mRNA expression level significantly increased from $24 \mathrm{hpi}$ and up to 40 folds at $48 \mathrm{hpi}$, which was initiated a little earlier than other downstream proteins of PERK. We speculated that CHOP was sensitized and activated by another signal cascade (Li et al. 2020). These results showed that PRV infection activated the PERK pathway. IRE1 was critical for the UPR, as it stimulated associated proteins in ER stress. Our results revealed that during PRV infection, the IRE1 pathway was induced at $36 \mathrm{hpi}$, as demonstrated by the presence of sXBP1 and upregulation of $\mathrm{p} 58^{\mathrm{IPK}}$, which played a necessary role in the regulation of protein biosynthesis and folding. Although ATF6, a type II ER transmembrane protein, has been verified with a stress sensing domain in the ER lumen and basic region/leucine zipper (bZIP) domain in the cytosol (Wang and Kaufman 2016), cleaved ATF6 was not found in this work, and other changes of downstream proteins involved ATF6 pathway were also not observed during PRV infection, suggesting the ATF6 pathway was not triggered by PRV infection.

Besides the well-established role of ER stress, several researchers have reported that ER stress has more association with cells apoptosis, autophagy, and innate immunity responses for some viruses (Fung and Liu 2014; Bettigole and Glimcher 2015; Mehrbod et al. 2019). Li and colleagues reported that Newcastle disease virus (NDV) promoted cells apoptosis and cytokines secretion by the induction of elF2a-CHOP- 
BCL-2/JNK and IRE1a-XBP1/JNK signaling cascades, contributing to NDV proliferation (Li et al. 2019). Porcine circovirus type 2 (PCV2) infection or Cap expression induced open reading frame 3 (ORF3)independent apoptosis by increased cellular reactive oxygen species (ROS) levels and cytosolic and mitochondrial $\mathrm{Ca}^{2+}$ levels (Zhou et al. 2016; Zhang et al. 2019b). Avian metapneumovirus subgroup C induced autophagy through the ATF6 UPR pathway (Hou et al. 2017), and the IRE1 of ER stress subsequently stimulated natural killer cell immunity in part by regulating c-Myc in NK cells (Dong et al. 2019).

As an ER stress inducer with the typical function of inhibiting Ca2+-ATPase (Wen et al. 2020), Tg with optimum concentration $(0.005$ and $0.01 \mu \mathrm{M})$ enormously enhanced PRV proliferation in suspensioncultured BHK-21 cells. On the contrary, PRV titer decreased significantly with the increasing addition of TUDCA, ER stress inhibitors, which can relieve ER stress and stabilize the UPR (Kusaczuk 2019). Combined with the results achieved above, it could be concluded that PRV infection induced ER stress in suspension-cultured BHK-21 cells. Meanwhile, PRV took advantage of ER stress to accelerate its replication. Viroporins, such as coronaviruses, hepatitis $\mathrm{C}$ virus (HCV), and influenza A virus (IAV), had been demonstrated to localize to the host ER or its associated membrane networks and play crucial roles in the entry, genome replication, assembly, and release during virus infection (Nieva et al. 2012). Chikungunya (CHIKV) infection can selectively activate ATF6 and IRE1, but suppress the PERK pathway since CHIKV non-structural protein 4 (nsP4) significantly reduced the phosphorylation (Ser 51) of elF2a to ensure translation of viral proteins (Rathore et al. 2013). Classical swine fever virus can efficiently mediate calcium permeability in the ER by utilizing p7 protein (Gladue et al. 2018). Therefore, the interaction between ER stress-associated proteins and PRV structural or non-structural proteins would be the major concern in future work.

In summary, our study reported that PRV infection induced ER stress and UPR activation in suspensioncultured BHK-21 cells (Fig. 7). The results indicated that the activation of the PERK and IRE1 pathways could benefit PRV replication in suspension-cultured BHK-21 cells, and the glycoprotein B played a key role in ER stress. These data offered details about the intracellular signaling events in PRV infected cells and extended our perspective regarding the mechanisms of ER stress and the UPR pathways.

\section{Declarations}

\section{Author contributions}

Conceptualization and experimental design: GMJ, FL, CL; methodology: $\mathrm{CL}, \mathrm{NMS}, \mathrm{XY}, \mathrm{BX}$; data curation: $\mathrm{CL}, \mathrm{NMS}, \mathrm{GMJ}$ and FL; investigation: $\mathrm{CL}, \mathrm{XY}, \mathrm{GMJ}$ and FL; Manuscript preparation: $\mathrm{CL}, \mathrm{WA}, \mathrm{ZTH}$, GMJ and FL. All authors have read and agreed to the published version of the manuscript.

\section{Funding}

This research was supported and funded by the Key Research and Development Project of Jiangsu Province (Modern Agriculture, BE2020407). 


\section{Data availability}

Data is available by upon request.

\section{Code availability}

Not applicable.

\section{Ethics approval}

Not applicable.

\section{Consent to participate}

Not applicable.

\section{Consent for publication}

Not applicable.

\section{Conflicts of interest/competing interests}

Not applicable.

\section{References}

1. Bettigole SE, Glimcher LH (2015) Endoplasmic reticulum stress in immunity. Annu Rev Immunol 33: 107-138

2. Blazquez AB, Escribano-Romero E, Merino-Ramos T, Saiz JC, Martin-Acebes MA (2014) Stress responses in flavivirus-infected cells: activation of unfolded protein response and autophagy. Front Microbiol 5: 266

3. Connolly SA, Jardetzky TS, Longnecker R (2021) The structural basis of herpesvirus entry. Nat Rev Microbiol 19: 110-121

4. Deng H, Gong B, Yang Z, Li Z, Zhou H, Zhang Y, Niu X, Liu S, Wei D (2019) Intensive Distribution of G(2)-Quaduplexes in the Pseudorabies Virus Genome and Their Sensitivity to Cations and GQuadruplex Ligands. Molecules 24: 774

5. Dong H, Adams NM, Xu Y, Cao J, Allan DSJ, Carlyle JR, Chen X, Sun JC, Glimcher LH (2019) The IRE1 endoplasmic reticulum stress sensor activates natural killer cell immunity in part by regulating cMyc. Nat Immunol 20: 865-878

6. Ellgaard L, Sevier CS, Bulleid NJ (2018) How Are Proteins Reduced in the Endoplasmic Reticulum? Trends Biochem Sci 43: 32-43

7. Fung TS, Huang M, Liu DX (2014) Coronavirus-induced ER stress response and its involvement in regulation of coronavirus-host interactions. Virus Res 194: 110-123 
8. Fung TS, Liu DX (2014) Coronavirus infection, ER stress, apoptosis and innate immunity. Front Microbiol 5: 296

9. Fung TS, Torres J, Liu DX (2015) The Emerging Roles of Viroporins in ER Stress Response and Autophagy Induction during Virus Infection. Viruses 7: 2834-2857

10. Gladue DP, Largo E, Holinka LG, Ramirez-Medina E, Vuono EA, Berggren KA, Risatti GR, Nieva JL, Borca MV (2018) Classical Swine Fever Virus p7 Protein Interacts with Host Protein CAMLG and Regulates Calcium Permeability at the Endoplasmic Reticulum. Viruses 10: 460

11. He W, Xu H, Gou H, Yuan J, Liao J, Chen Y, Fan S, Xie B, Deng S, Zhang Y, Chen J, Zhao M (2017) CSFV Infection Up-Regulates the Unfolded Protein Response to Promote Its Replication. Front Microbiol 8: 2129

12. Hetz C, Papa FR (2018) The Unfolded Protein Response and Cell Fate Control. Mol Cell 69: 169-181

13. Hou L, Wei L, Zhu S, Wang J, Quan R, Li Z, Liu J (2017) Avian metapneumovirus subgroup C induces autophagy through the ATF6 UPR pathway. Autophagy 13: 1709-1721

14. Ibrahim IM, Abdelmalek DH, Elfiky AA (2019) GRP78: A cell's response to stress. Life Sci 226: 156163

15. Isler JA, Skalet AH, Alwine JC (2005) Human cytomegalovirus infection activates and regulates the unfolded protein response. J Virol 79: 6890-6899

16. Jaud M, Philippe C, Van Den Berghe L, Segura C, Mazzolini L, Pyronnet S, Laurell H, Touriol C (2019) The PERK Branch of the Unfolded Protein Response Promotes DLL4 Expression by Activating an Alternative Translation Mechanism. Cancers (Basel) 11: 142

17. Jiang X, Kanda T, Haga Y, Sasaki R, Nakamura M, Wu S, Nakamoto S, Shirasawa H, Okamoto H, Yokosuka $O$ (2017) Glucose-regulated protein 78 is an antiviral against hepatitis A virus replication. Exp Ther Med 13: 3305-3308

18. Jin JK, Blackwood EA, Azizi K, Thuerauf DJ, Fahem AG, Hofmann C, Kaufman RJ, Doroudgar S, Glembotski CC (2017) ATF6 Decreases Myocardial Ischemia/Reperfusion Damage and Links ER Stress and Oxidative Stress Signaling Pathways in the Heart. Circ Res 120: 862-875

19. Johnston BP, Pringle ES, McCormick C (2019) KSHV activates unfolded protein response sensors but suppresses downstream transcriptional responses to support lytic replication. PLoS Pathog 15: e1008185

20. Karagoz GE, Acosta-Alvear D, Nguyen HT, Lee CP, Chu F, Walter P (2017) An unfolded protein-induced conformational switch activates mammalian IRE1. eLife 6: e30700

21. Karagoz GE, Acosta-Alvear D, Walter P (2019) The Unfolded Protein Response: Detecting and Responding to Fluctuations in the Protein-Folding Capacity of the Endoplasmic Reticulum. Cold Spring Harb Perspect Biol 11: a033886

22. Klupp BG, Hengartner CJ, Mettenleiter TC, Enquist LW (2004) Complete, annotated sequence of the pseudorabies virus genome. J Virol 78: 424-440 
23. Kopp MC, Larburu N, Durairaj V, Adams CJ, Ali MMU (2019) UPR proteins IRE1 and PERK switch BiP from chaperone to ER stress sensor. Nat Struct Mol Biol 26: 1053-1062

24. Kusaczuk M (2019) Tauroursodeoxycholate-Bile Acid with Chaperoning Activity: Molecular and Cellular Effects and Therapeutic Perspectives. Cells 8

25. Li C, Fan Q, Quan H, Nie M, Luo Y, Wang L (2018) The three branches of the unfolded protein response exhibit differential significance in breast cancer growth and stemness. Exp Cell Res 367: 170-185

26. Li T, Xu XH, Guo X, Yuan T, Tang ZH, Jiang XM, Xu YL, Zhang LL, Chen X, Zhu H, Shi JJ, Lu JJ (2020) Activation of notch $3 / \mathrm{c}-\mathrm{MYC} / \mathrm{CHOP}$ axis regulates apoptosis and promotes sensitivity of lung cancer cells to mTOR inhibitor everolimus. Biochem Pharmacol 175: 113921

27. Li Y, Jiang W, Niu Q, Sun Y, Meng C, Tan L, Song C, Qiu X, Liao Y, Ding C (2019) elF2alpha-CHOP-BCl2/JNK and IRE1 alpha-XBP1/JNK signaling promote apoptosis and inflammation and support the proliferation of Newcastle disease virus. Cell Death Dis 10: 891

28. Liao Y, Fung TS, Huang M, Fang SG, Zhong Y, Liu DX (2013) Upregulation of CHOP/GADD153 during coronavirus infectious bronchitis virus infection modulates apoptosis by restricting activation of the extracellular signal-regulated kinase pathway. J Virol 87: 8124-8134

29. Liu Y, Jiang ZY, Zhou YL, Qiu HH, Wang G, Luo Y, Liu JB, Liu XW, Bu WQ, Song J, Cui L, Jia XB, Feng L (2017) beta-elemene regulates endoplasmic reticulum stress to induce the apoptosis of NSCLC cells through PERK/IRE1alpha/ATF6 pathway. Biomed Pharmacother 93: 490-497

30. Mehrbod P, Ande SR, Alizadeh J, Rahimizadeh S, Shariati A, Malek H, Hashemi M, Glover KKM, Sher AA, Coombs KM, Ghavami S (2019) The roles of apoptosis, autophagy and unfolded protein response in arbovirus, influenza virus, and HIV infections. Virulence 10: 376-413

31. Mukhopadhyay S, Kuhn RJ, Rossmann MG (2005) A structural perspective of the flavivirus life cycle. Nat Rev Microbiol 3: 13-22

32. Neerukonda SN, Katneni UK, Bott M, Golovan SP, Parcells MS (2018) Induction of the unfolded protein response (UPR) during Marek's disease virus (MDV) infection. Virology 522: 1-12

33. Nieva JL, Madan V, Carrasco L (2012) Viroporins: structure and biological functions. Nat Rev Microbiol 10: 563-574

34. Rathore AP, Ng ML, Vasudevan SG (2013) Differential unfolded protein response during Chikungunya and Sindbis virus infection: CHIKV nsP4 suppresses elF2alpha phosphorylation. Virol J 10: 36

35. Reid DW, Campos RK, Child JR, Zheng T, Chan KWK, Bradrick SS, Vasudevan SG, Garcia-Blanco MA, Nicchitta CV (2018) Dengue Virus Selectively Annexes Endoplasmic Reticulum-Associated Translation Machinery as a Strategy for Co-opting Host Cell Protein Synthesis. J Virol 92

36. Ron D, Walter $P$ (2007) Signal integration in the endoplasmic reticulum unfolded protein response. Nat Rev Mol Cell Biol 8: 519-529

37. Sharma M, Bhattacharyya S, Sharma KB, Chauhan S, Asthana S, Abdin MZ, Vrati S, Kalia M (2017) Japanese encephalitis virus activates autophagy through XBP1 and ATF6 ER stress sensors in neuronal cells. J Gen Virol 98: 1027-1039

Page $12 / 22$ 
38. Sun Y, Luo Y, Wang CH, Yuan J, Li N, Song K, Qiu HJ (2016) Control of swine pseudorabies in China: Opportunities and limitations. Vet Microbiol 183: 119-124

39. Tan Z, Zhang W, Sun J, Fu Z, Ke X, Zheng C, Zhang Y, Li P, Liu Y, Hu Q, Wang H, Zheng Z (2018) ZIKV infection activates the IRE1-XBP1 and ATF6 pathways of unfolded protein response in neural cells. $J$ Neuroinflammation 15: 275

40. Walter P, Ron D (2011) The unfolded protein response: from stress pathway to homeostatic regulation. Science 334: 1081-1086

41. Wang J, Song Z, Ge A, Guo R, Qiao Y, Xu M, Wang Z, Liu Y, Zheng Y, Fan H, Hou J (2018) Safety and immunogenicity of an attenuated Chinese pseudorabies variant by dual deletion of TK\&gE genes. BMC Vet Res 14: 287

42. Wang M, Kaufman RJ (2016) Protein misfolding in the endoplasmic reticulum as a conduit to human disease. Nature 529: 326-335

43. Wen G, Eder K, Ringseis R (2020) 1,25-hydroxyvitamin D3 decreases endoplasmic reticulum stressinduced inflammatory response in mammary epithelial cells. PLoS ONE 15: e0228945

44. Xue M, Fu F, Ma Y, Zhang X, Li L, Feng L, Liu P (2018) The PERK Arm of the Unfolded Protein Response Negatively Regulates Transmissible Gastroenteritis Virus Replication by Suppressing Protein Translation and Promoting Type I Interferon Production. J Virol 92:e00431-18

45. Yang S, Pei Y, Zhao A (2017) iTRAQ-based Proteomic Analysis of Porcine Kidney Epithelial PK15 cells Infected with Pseudorabies virus. Sci Rep 7: 45922

46. Yang S, Zhu J, Zhou X, Wang H, Li X, Zhao A (2019) Induction of the unfolded protein response (UPR) during pseudorabies virus infection. Vet Microbiol 239: 108485

47. Zhang L, Wang A (2012) Virus-induced ER stress and the unfolded protein response. Front Plant Sci 3: 293

48. Zhang P, Lv L, Sun H, Li S, Fan H, Wang X, Bai J, Jiang P (2019a) Identification of linear B cell epitope on $\mathrm{gB}, \mathrm{gC}$, and $\mathrm{gE}$ proteins of porcine pseudorabies virus using monoclonal antibodies. Vet Microbiol 234: 83-91

49. Zhang Y, Sun R, Geng S, Shan Y, Li X, Fang W (2019b) Porcine Circovirus Type 2 Induces ORF3Independent Mitochondrial Apoptosis via PERK Activation and Elevation of Cytosolic Calcium. J Virol 93: e01784-18

50. Zhao A, Zhang Z, Zhou Y, Li X, Li X, Ma B, Zhang Q (2020) beta-Elemonic acid inhibits the growth of human Osteosarcoma through endoplasmic reticulum (ER) stress-mediated PERK/elF2alpha/ATF4/CHOP activation and Wnt/beta-catenin signal suppression. Phytomedicine 69: 153183

51. Zhao D, Yang J, Han K, Liu Q, Wang H, Liu Y, Huang X, Zhang L, Li Y (2019) The unfolded protein response induced by Tembusu virus infection. BMC Vet Res 15: 34

52. Zhou J, Li S, Wang X, Zou M, Gao S (2017) Bartha-k61 vaccine protects growing pigs against challenge with an emerging variant pseudorabies virus. Vaccine 35: 1161-1166 
53. Zhou Y, Qi B, Gu Y, Xu F, Du H, Li X, Fang W (2016) Porcine Circovirus 2 Deploys PERK Pathway and GRP78 for Its Enhanced Replication in PK-15 Cells. Viruses 8: pii: E56

54. Zou D, Xu J, Duan X, Xu X, Li P, Cheng L, Zheng L, Li X, Zhang Y, Wang X, Wu X, Shen Y, Yao X, Wei J, Yao L, Li L, Song B, Ma J, Liu X, Wu Z, Zhang H, Cao H (2019) Porcine epidemic diarrhea virus ORF3 protein causes endoplasmic reticulum stress to facilitate autophagy. Vet Microbiol 235: 209-219

\section{Table}

Table 1 Primers used in this study 


\begin{tabular}{|c|c|c|c|}
\hline Gene & Primer sequence $\left(5^{\prime}-3^{\prime}\right)$ & Size/bp & Application \\
\hline \multirow[t]{2}{*}{ GRP78 } & F: TCATCGGACGCACTTGGAA & 162 & qRT-PCR \\
\hline & R: TAGTGAGAACCATGGCAGAA & & \\
\hline \multirow[t]{2}{*}{ GRP94 } & F: CCGAGTTTGATGGGAAGAGGTT & 206 & qRT-PCR \\
\hline & R: GGCCACAAGAGCACAAGGAGAT & & \\
\hline \multirow[t]{2}{*}{ ATF4 } & F: AGCAAAACAAGACAGCAGCCACTA & 177 & qRT-PCR \\
\hline & R: TTGCCTTACGGACCTCCTCTATCA & & \\
\hline \multirow[t]{2}{*}{$\mathrm{CHOP}$} & F: AAGAGGAAGATCAAGGAAGAACTA & 207 & qRT-PCR \\
\hline & R: CCATGCGGTCAATCAGAG & & \\
\hline \multirow[t]{2}{*}{ GADD34 } & F: AGCAGCTGACCGAGGCAAGAG & 144 & qRT-PCR \\
\hline & R: TTAGGGGCGGTCCAAGGTGA & & \\
\hline \multirow[t]{2}{*}{ XBP1 } & F: GAGAAGGCGCTGCGGAGGAAACTG & 530 & RT-PCR \\
\hline & R: GAGAAAGGGAGGCTGGTAAGGAAC & & \\
\hline \multirow[t]{2}{*}{ p58 IPK } & F: AGATGGCGACCCTGATAACTA & 246 & qRT-PCR \\
\hline & R: GACTGGGCTTCCTTCTCTTC & & \\
\hline \multirow[t]{2}{*}{ EDEM1 } & F: GGAAGTCTCCTTTCTGCTCATAG & 155 & qRT-PCR \\
\hline & R: GGAATCCCTGTCTTGGTGTT & & \\
\hline \multirow[t]{2}{*}{ Calnexin } & F: TGCCGAGCCAGGTGTAGTG & 230 & qRT-PCR \\
\hline & R: CСТCTTCATCССССTTGTTCTT & & \\
\hline \multirow[t]{2}{*}{ Calreticulin } & F: GGAGCCTGCCGTCTACTTC & 220 & qRT-PCR \\
\hline & R: GGTCTGGCCCTTGTTACTGA & & \\
\hline \multirow[t]{2}{*}{ ERp57 } & F: CTAGGACTGCCGATGGGATTGT & 180 & qRT-PCR \\
\hline & R: AGTTGCTGGCTGCTTTTAGGAA & & \\
\hline \multirow[t]{2}{*}{ PDI } & F: CCCCGGAGGAGGAGGACAAC & 105 & qRT-PCR \\
\hline & R: CACACCACGGGGCATAGAAC & & \\
\hline \multirow[t]{2}{*}{$\beta$-actin } & F: CCAGGTCATCACCATTGGCAACG & 153 & qRT-PCR \\
\hline & R: TTGGCATAGAGGTCTTTGCGGATGT & & \\
\hline
\end{tabular}




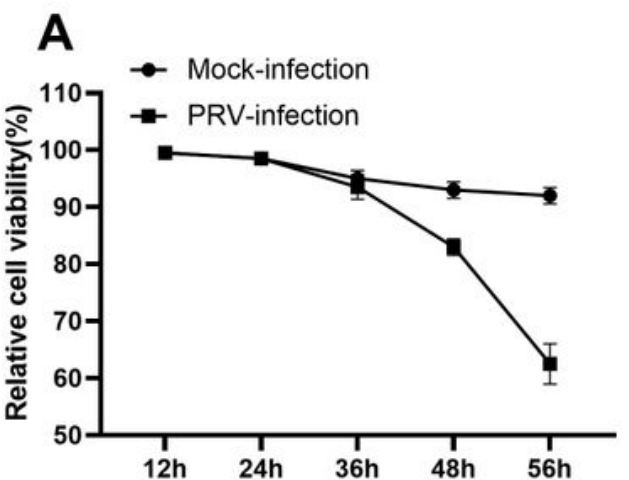

B

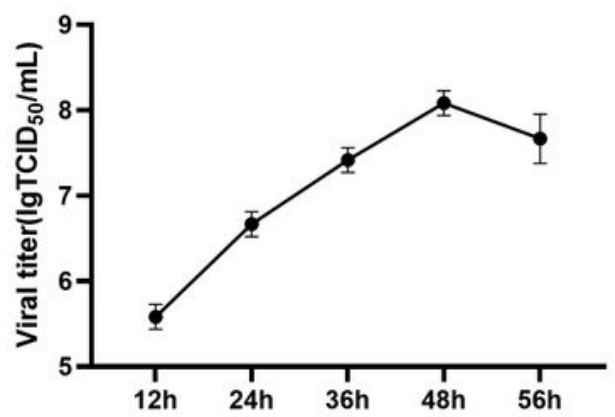

C

Mock-infection

PRV-infection

\section{2h $24 \mathrm{~h} \quad 36 \mathrm{~h} \quad 48 \mathrm{~h} \quad 12 \mathrm{~h} \quad 24 \mathrm{~h} \quad 36 \mathrm{~h} \quad 48 \mathrm{~h}$}

GRP78

GRP94

GAPDH

D
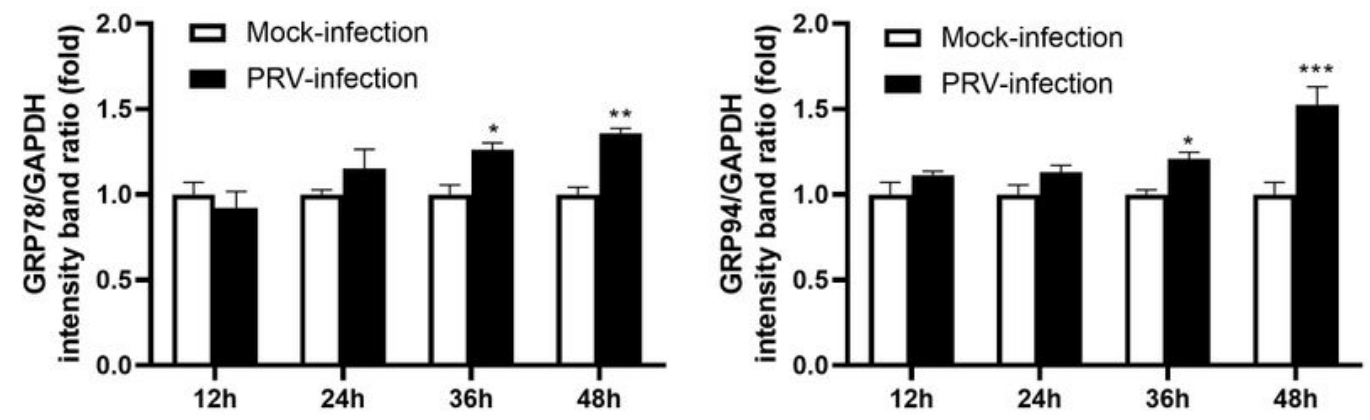

E

GRP78

\section{GRP94}
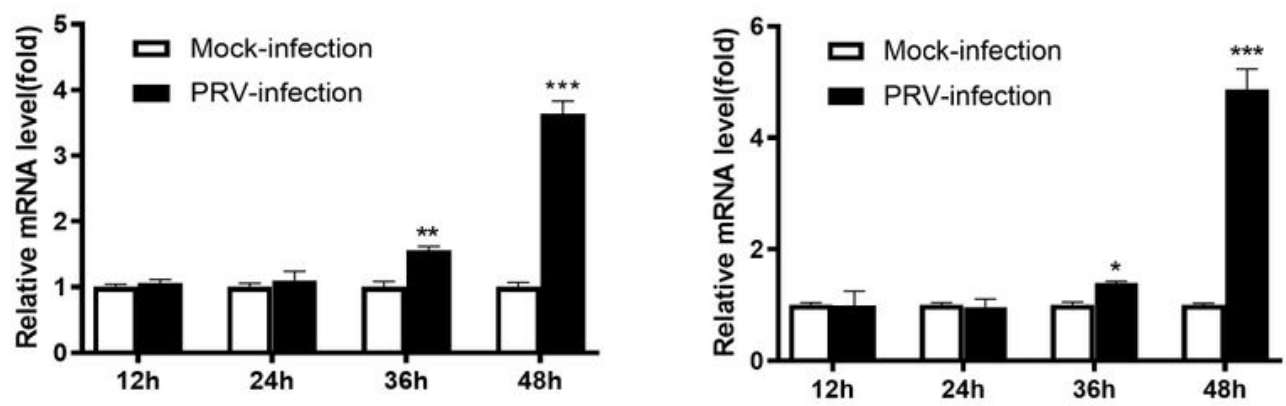

Figure 1

PRV infection induced ER stress in suspension-cultured BHK-21 cells. The cells were infected by PRV at an $\mathrm{MOI}$ of 0.01 . Mock-infection and PRV-infection cell samples were collected at indicated time points. (A) The profile of relative cell viability of mock-infection and PRV-infection cells. (B) The profile of viral titer of PRV-infection cells. (C) The protein levels of GRP78 and GRP94 were confirmed by western blot; GAPDH was used as a loading control. (D) The relative expression of the targeted proteins/GAPDH was 
analyzed by densitometric scanning. (E) The transcriptional levels of GRP78 and GRP94 were measured by qRT-PCR at different time points from 12 to $48 \mathrm{~h}$ using $\beta$-actin as the reference gene. Means and SD of the results from three independent experiments are shown; Two-way ANOVA: $* P<0.05 ; * * P<0.01$; $* * * P<0.001$.

A
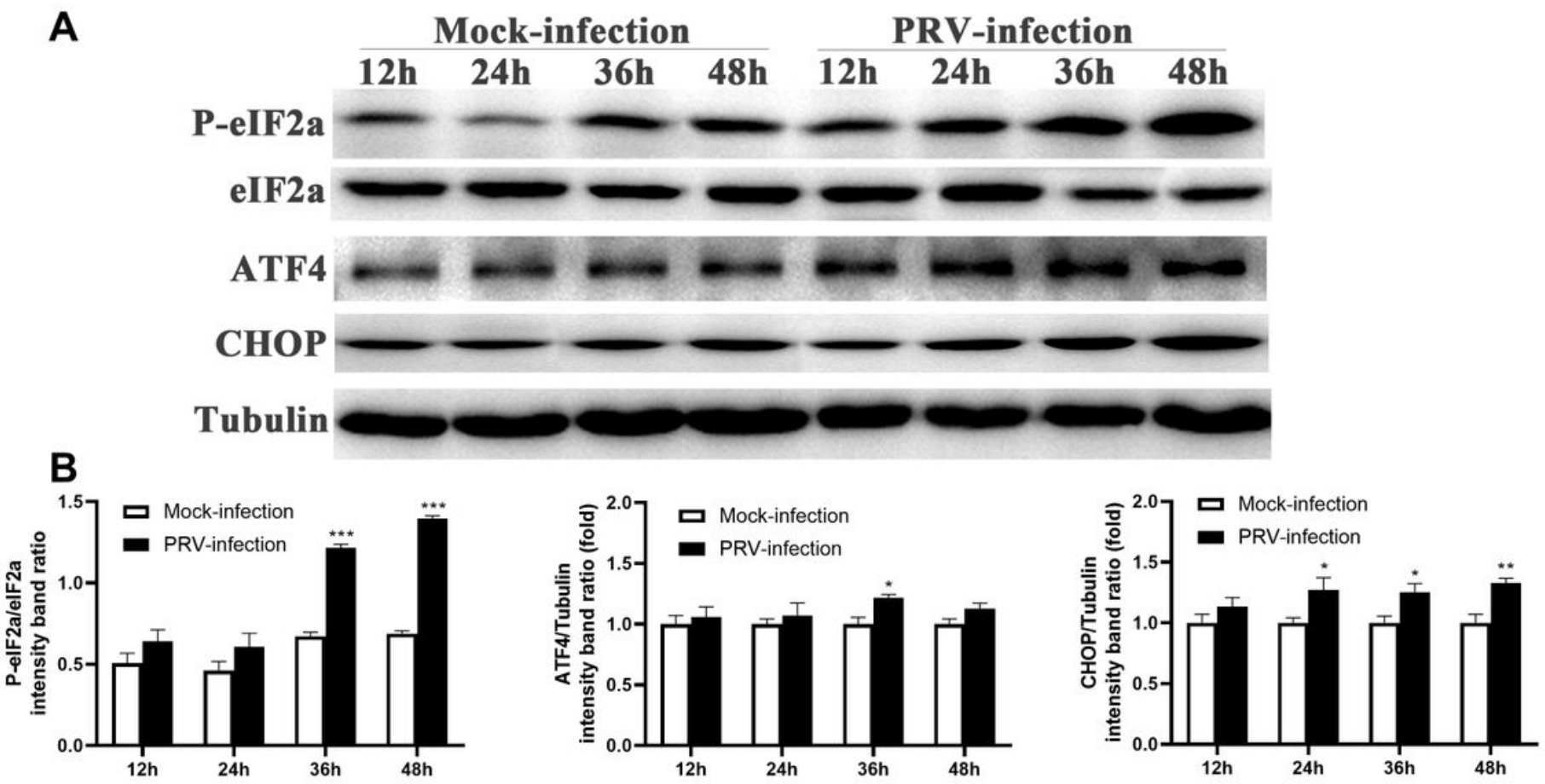

C

ATF4

CHOP
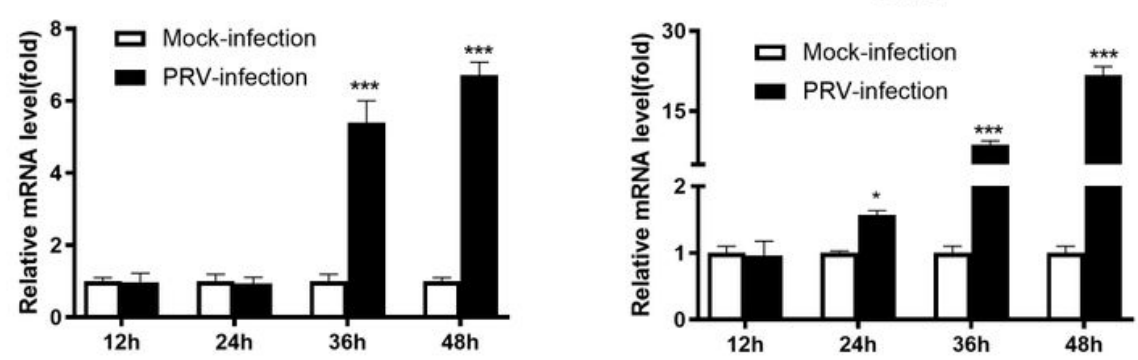

GADD34

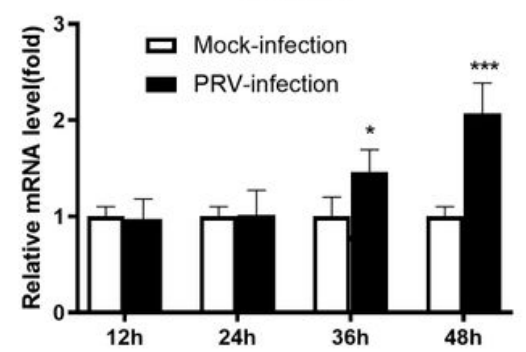

Figure 2

PRV infection activated the PERK pathway in suspension-cultured BHK-21 cells. The cells were infected by PRV at an MOI of 0.01 . Mock-infection and PRV-infection cell pellets were collected at $12,24,36$, and 48 h. (A) The protein levels of total elF2a, P-elF2a, ATF4, and CHOP were confirmed by western blot; Tubulin was used as a loading control. (B) The relative expression of the targeted proteins/Tubulin was analyzed by densitometric scanning. (C) The transcriptional levels of the PERK downstream pathway ATF4, CHOP, and GADD34 were measured by qRT-PCR at different time points from 12 to $48 \mathrm{~h}$ using $\beta$ actin as the reference gene. Means and SD of the results from three independent experiments are shown; Two-way ANOVA: $* P<0.05 ; * * P<0.01 ; * * * P<0.001$. 
A

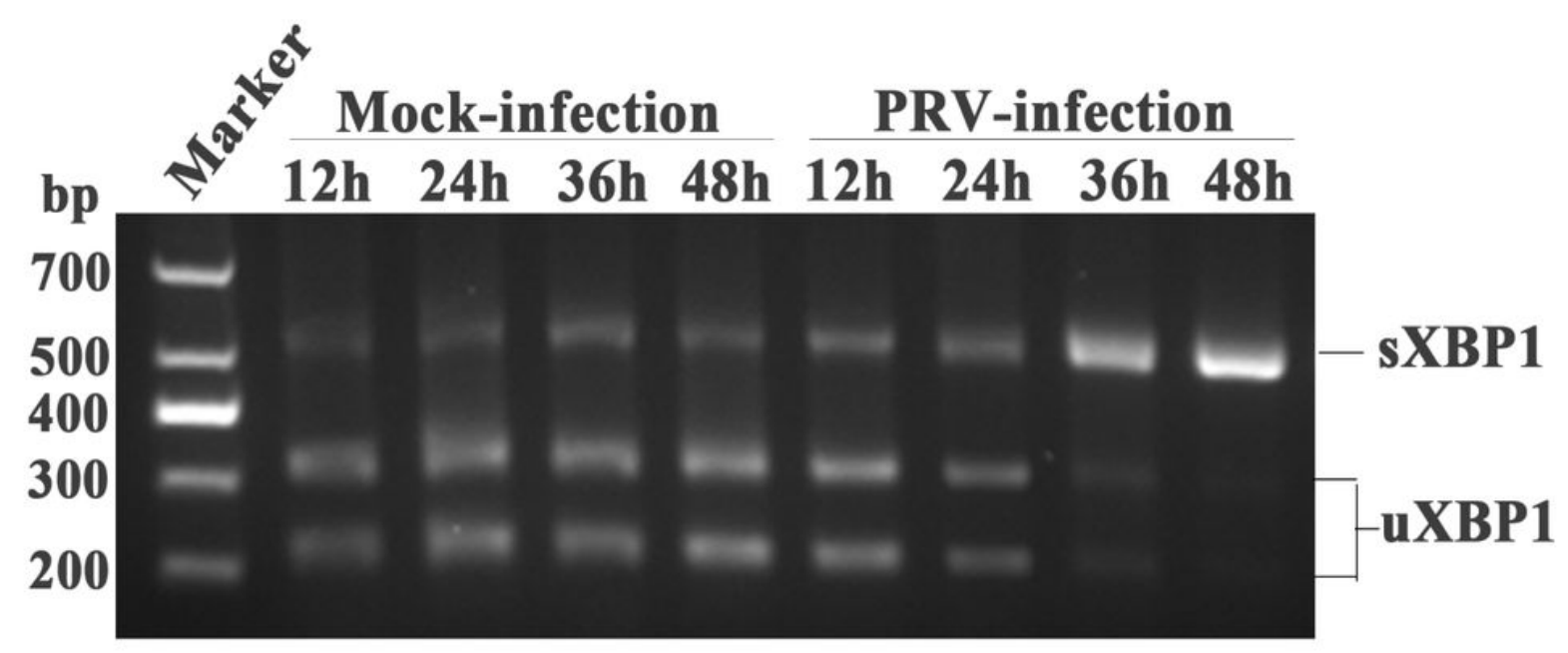

B

$\mathrm{p} 58^{\mathrm{IPK}}$

EDEM1
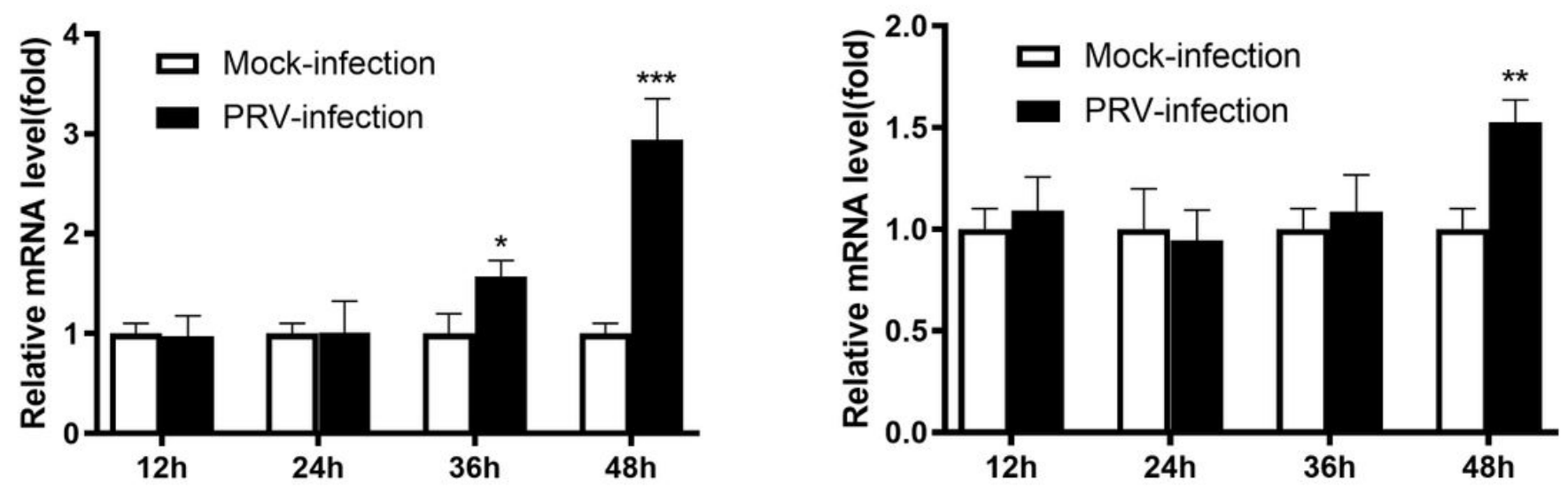

Figure 3

PRV infection activated the IRE pathway in suspension-cultured BHK-21 cells. The cells were infected by PRV at an MOI of 0.01. Mock-infection and PRV-infection cell pellets were collected at $12,24,36$, and 48 h. (A) XBP1 mRNA was amplified by RT-PCR using XBP1-specific primers, after which the XBP1 fragment was digested by $P s t \mathrm{I}$, and the products were separated by $2 \%$ agarose gel electrophoresis. (B) The transcriptional levels of the IRE pathway downstream of $\mathrm{p} 58^{\mathrm{IPK}}$ and EDEM1 were measured by qRT-PCR at different time points from 12 to $48 \mathrm{~h}$ using $\beta$-actin as the reference gene. Means and SD of the results from three independent experiments are shown; Two-way ANOVA: $* P<0.05 ; * * P<0.01 ; * * * P<$ 0.001 . 
A
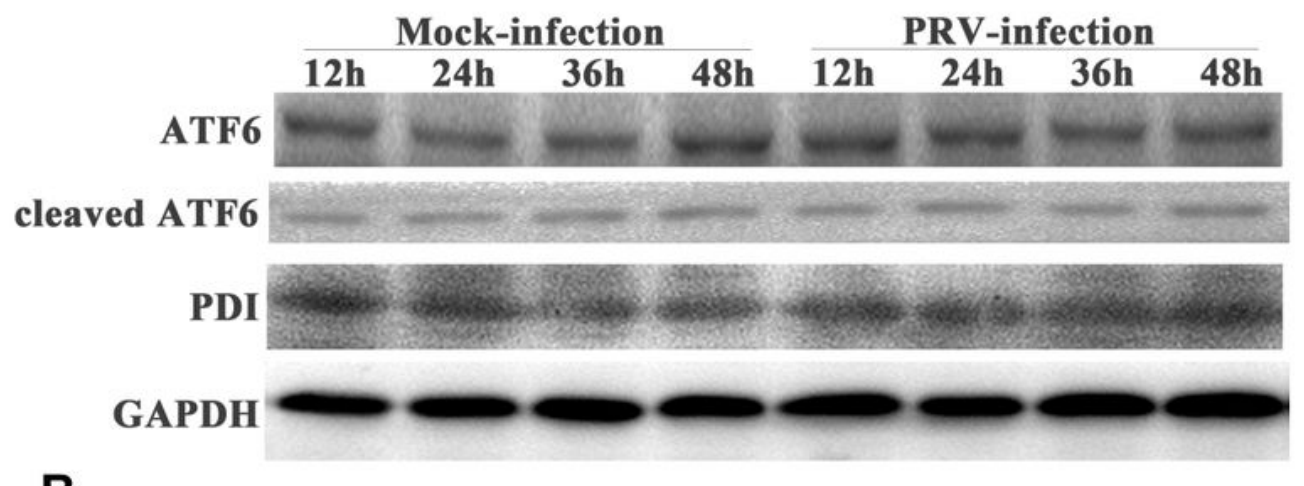

B
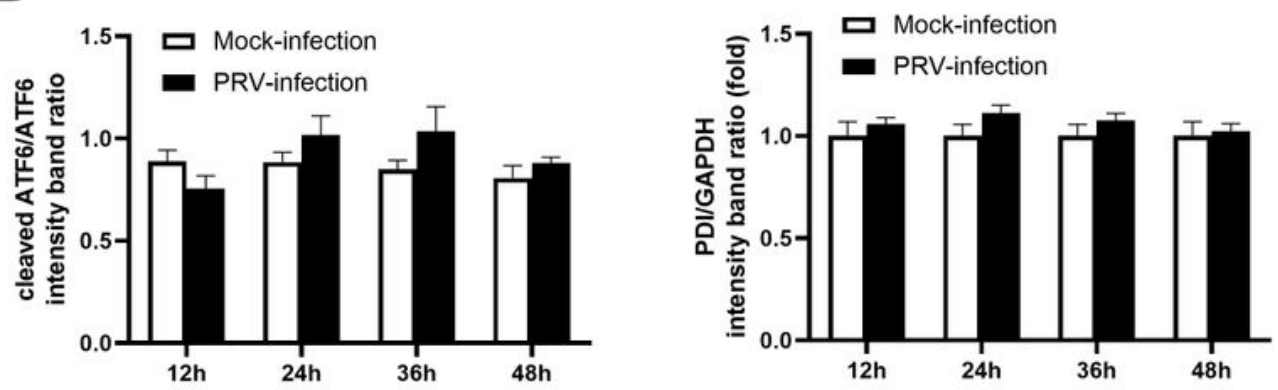

C Calnexin
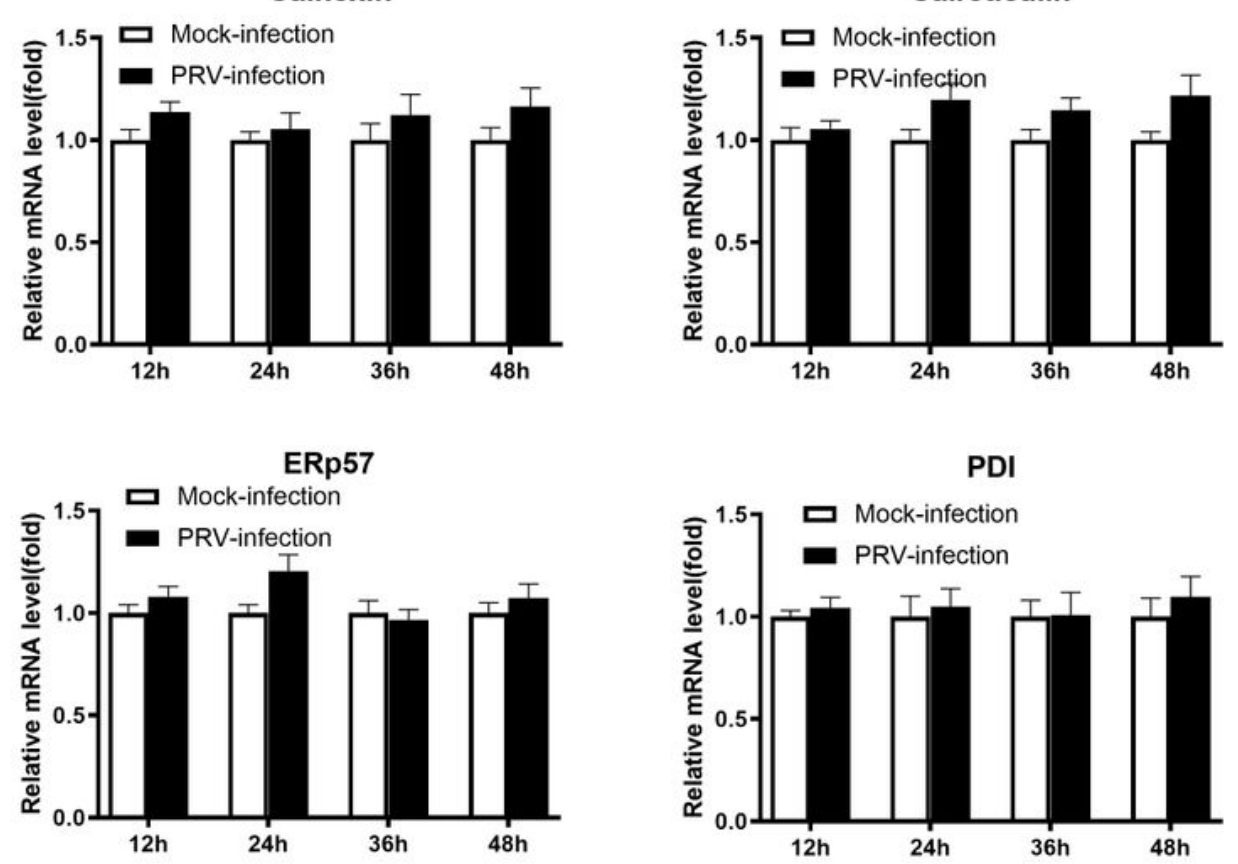

\section{Figure 4}

PRV infection didn't activate the ATF6 pathway in suspension-cultured BHK-21 cells. The cells were infected by PRV at an MOI of 0.01. Mock-infection and PRV-infection cell pellets were collected at 12, 24, 36, and $48 \mathrm{~h}$. (A) The protein levels of ATF6 and PDI were confirmed by western blot; GAPDH was used as a loading control. (B) The relative expression of the targeted proteins/GAPDH was analyzed by densitometric scanning. (C) The transcriptional levels of ATF6 pathway downstream Calnexin, 
Calreticulin, ERp57, and PDI were measured by qRT-PCR at different time points from 12 to $48 \mathrm{~h}$ using $\beta$ actin as the reference gene. Means and SD of the results from three independent experiments are shown; Two-way ANOVA: $* P<0.05 ; * * P<0.01 ; * * * P<0.001$.

A
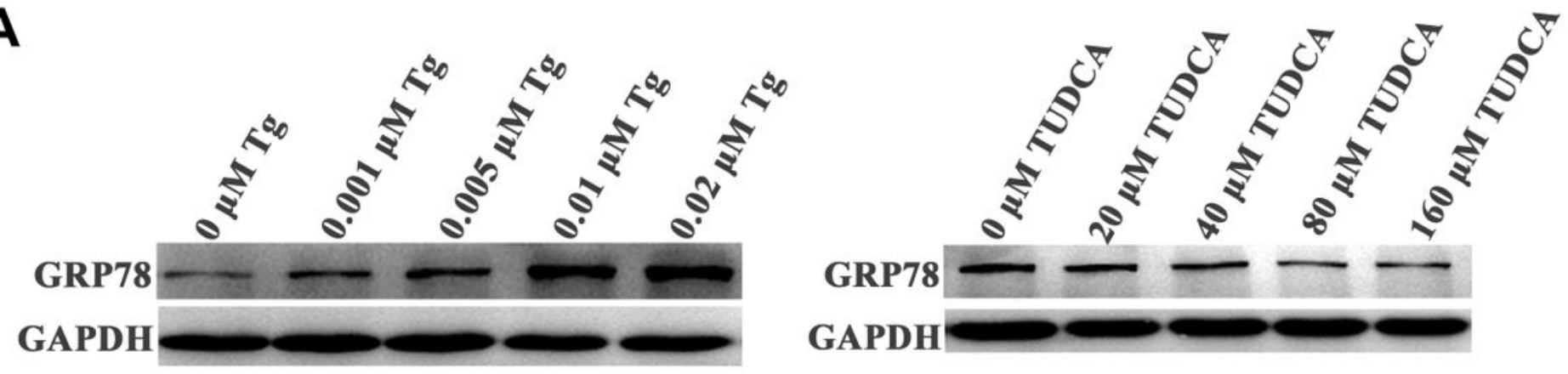

B
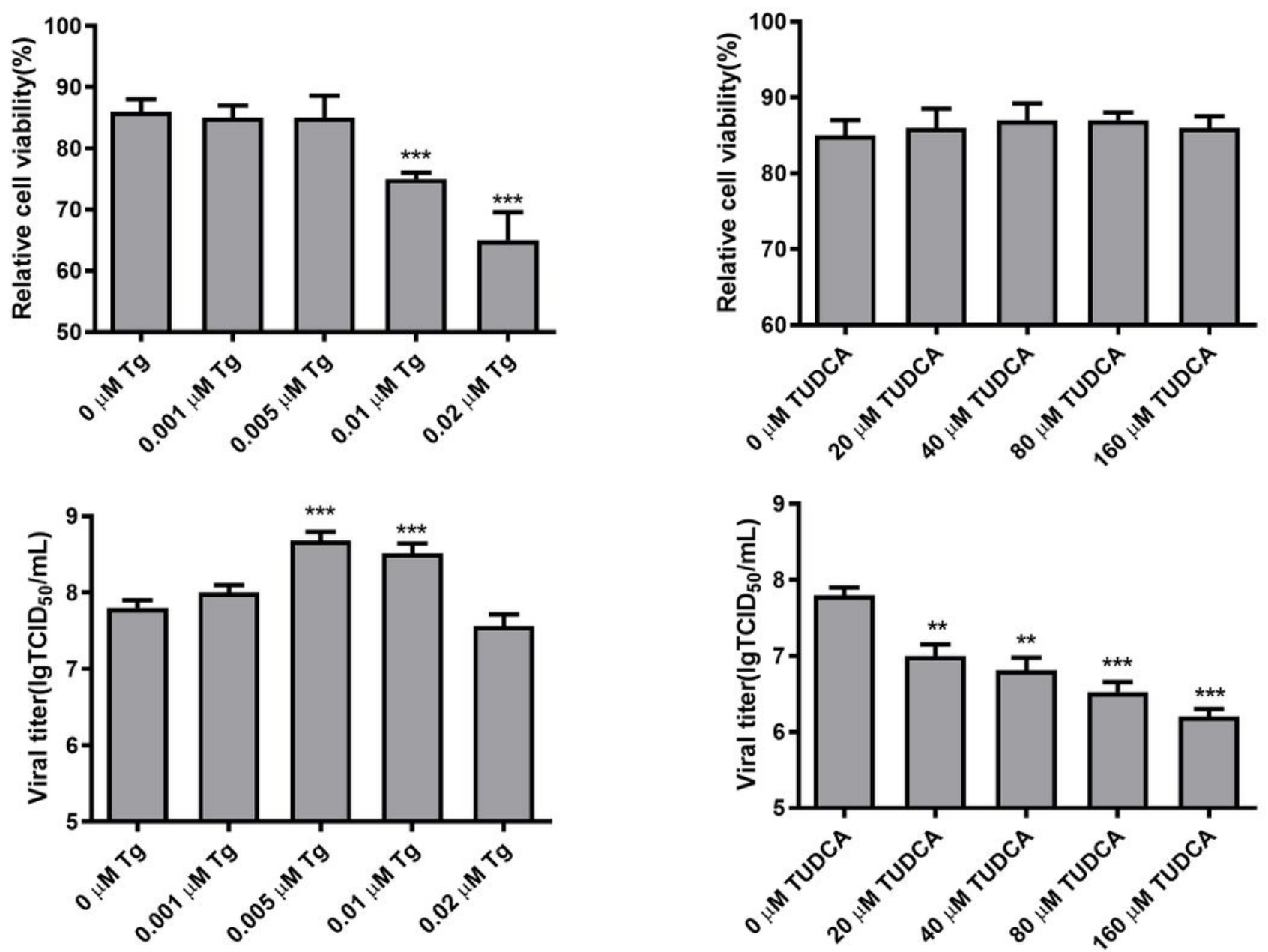

Figure 5

Chemicals of ER stress affected PRV infection. The suspension-cultured BHK-21 cells were treated with Tg concentrations of $0,0.001,0.005,0.01$, and $0.02 \mu \mathrm{M}$, TUDCA concentrations of $0,20,40,80$, and 160 $\mu \mathrm{M}$. (A) The ER stress level affected by Tg and TUDCA was analyzed by detecting the expression of 
GRP78 in mock-infection cells. (B) Relative cell viability was measured in mock-infection cells. (C) The cells added different concentrations of chemicals were infected by PRV for $48 \mathrm{~h}$. Viral titers were measured by $\mathrm{TCID}_{50}$, respectively. Means and $\mathrm{SD}$ of the results from three independent experiments are shown; Two-way ANOVA: $* P<0.05 ; * * P<0.01 ; * * * P<0.001$.

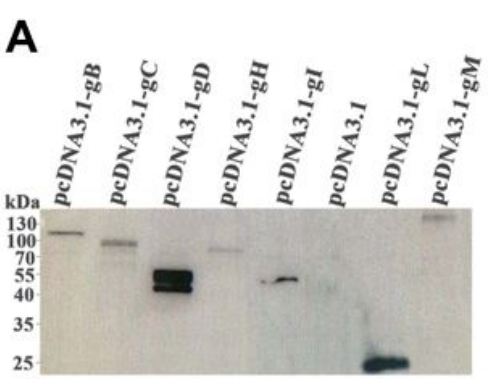

D
B

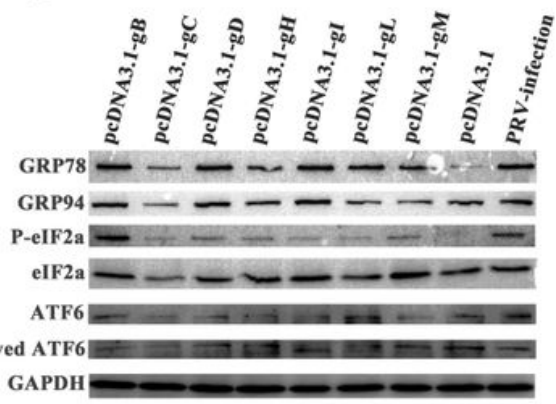

C

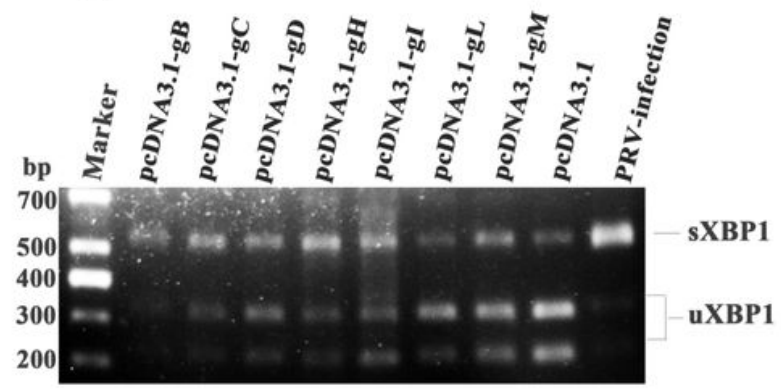

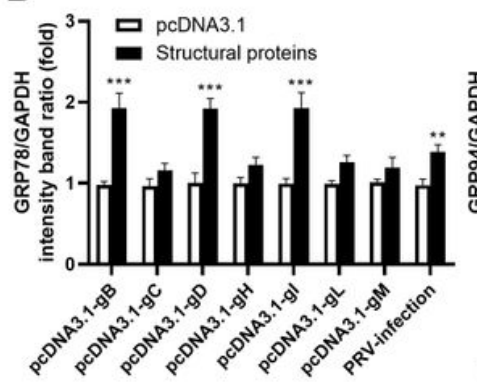
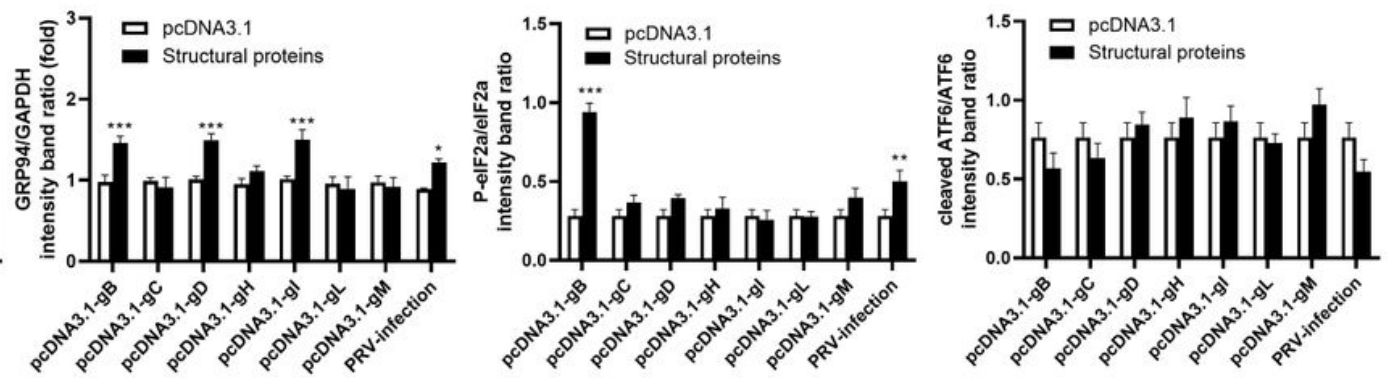

\section{Figure 6}

PRV structural proteins triggered UPR pathways. BHK-21 cells were transfected with pcDNA3.1 vector carrying target genes (glycoproteins $\mathrm{B}, \mathrm{C}, \mathrm{D}, \mathrm{H}, \mathrm{I}, \mathrm{L}$, or $\mathrm{M}$ ). The transfected with pcDNA3.1 empty vector and PRV-infection BHK-21 cells were used as negative and positive controls. (A)The overexpression of structural proteins in BHK-21 cells was confirmed by Western blot. (B)The protein levels of GRP78, GRP94, total elF2a, P-elF2a, and ATF6 were confirmed by Western blot; GAPDH was used as a loading control. (C) XBP1 mRNA of the overexpressed structural proteins was amplified by RT-PCR using XBP1specific primers, after which the XBP1 fragment was digested by Pst I, and the products were separated by $2 \%$ agarose gel electrophoresis. (D)The relative expression (B) of the targeted proteins/GAPDH was analyzed by densitometric scanning. 


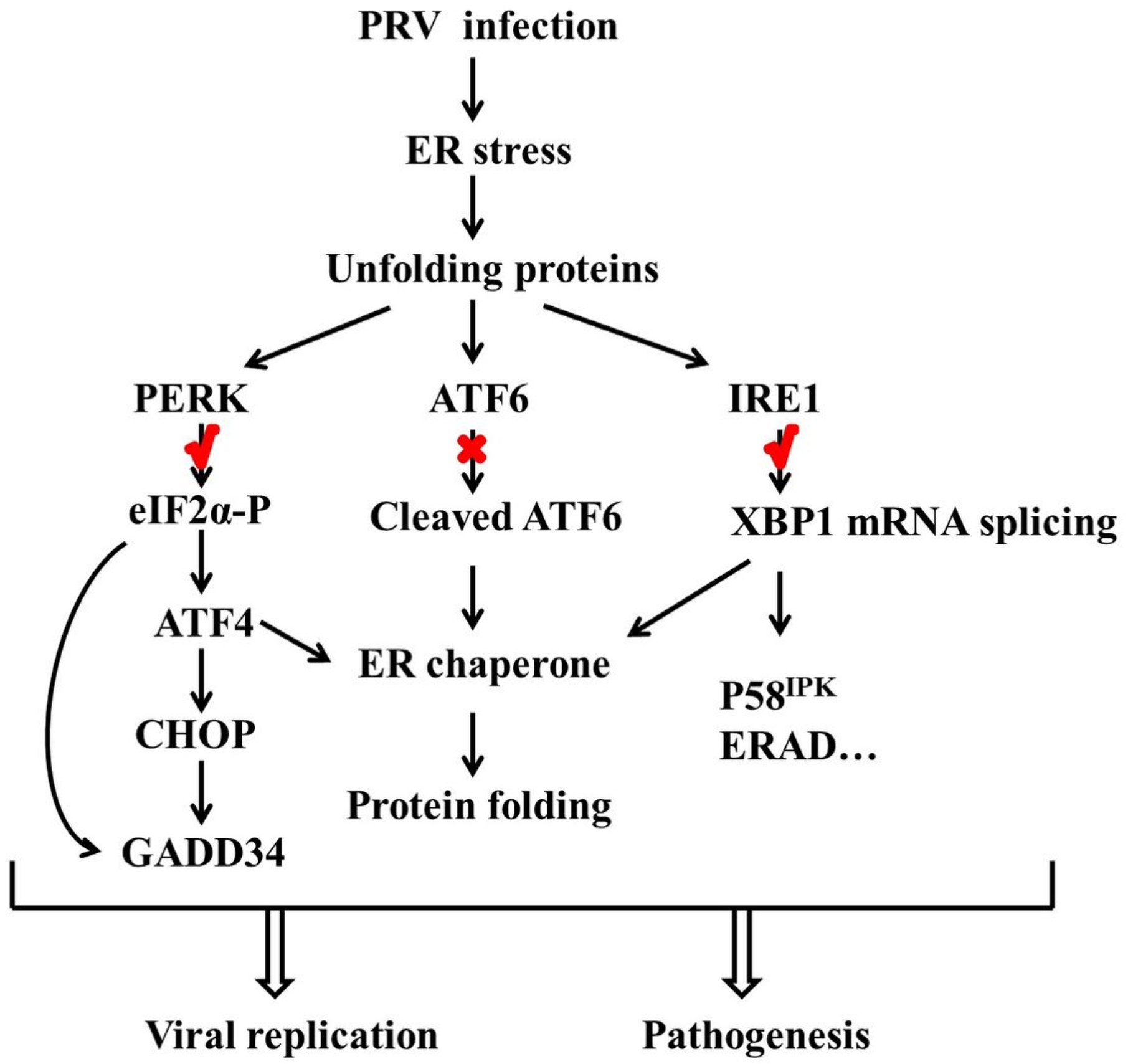

Figure 7

Schematic representation of PRV activation and influence over the UPR. PRV infection activated PERK and IRE1 pathways of UPR, but not the ATF6 pathway. Phosphorylated eiF2a upregulated the expression of ATF4, which induced the upregulation of CHOP and GADD34. GADD34 recruited PP1 to the ER to dephosphorylate eiF2 $a$ and promoted the return to homeostasis. Activated IRE1 facilitated the splicing of XBP1 mRNA, which encoded a transcription factor leading to the expression of the UPR target genes. Arrows represented the activation of components or processes in the ER stress pathways upon viral infection and pathogenesis. $\sqrt{\text { :activated; }} \times$ :non-activated. 